\title{
MULHERES ENCARCERADAS: A SAÚDE ATRÁS DAS GRADES
}

\author{
WOMEN IN JAIL: HEALTH BEHIND BARS
}

\section{Maria Auxiliadora Teixeira Ribeiro', Niedja Mara Silva Fontes de Deus ${ }^{2}$}

Autora para correspondência. Psicóloga. Doutora em Psicologia Social e docente na Universidade Federal de Alagoas. Maceió, Alagoas, Brasil. http://orcid.org/0000-0003-1023-3118. maria.ribeiro@ip.ufal.br ${ }^{2}$ Psicóloga especializada em clínica psicanalítica pelo Centro Universitário CESMAC. Maceió, Alagoas, Brasil. http://orcid.org/0000-0002-9105-4287.niedjamara88@hotmail.com

RESUMO I $O$ aumento significativo do encarceramento de mulheres no Brasil tem trazido impacto para as políticas de segurança, administração penitenciária, assim como para as políticas específicas à desigualdade de gênero. Este texto decorre do mapeamento da literatura acessada em banco de dados e objetiva ampliar a discussão sobre a saúde das mulheres no Sistema Prisional, focalizando o recorte de gênero que circula nos artigos nacionais e internacionais publicados entre 2004 e 2015 . Para construir o objeto de estudo, essas produções científicas foram acessadas nas bases de dados- Scientific Electronic Library Online (SCIELO); Periódicos da Coordenação de Aperfeiçoamento de Pessoal de Nível Superior (CAPES) e Biblioteca Virtual em Saúde (BVS) -utilizando descritores: mulheres na prisão e mulheres em cárcere. Foram selecionados 74 artigos, nos quais identificouse os temas: perfil(8), cotidiano(22), saúde(16), família(16), ressocialização(11) e mídia(1); as áreas de estudo em que foram produzidos: Enfermagem(5), Psicologia(15), Saúde Pública/Coletiva(16), Serviço Social(1), Medicina(10), Ciências Sociais(10), Direito(8), Educação (9); regiões e países. Foram selecionados os artigos identificados pela discussão de saúde e os subtemas foram definidos através dos resumos de cada texto e norteados pelo objetivo da pesquisa. Numa revisão dialógica da literatura, identificou-se que as produções apontam para as diferenças de gênero, sem apresentarem, entretanto, uma discussão sobre alguma teoria de gênero específica. Em sua maioria, referem-se ao gênero como todas as formas de construção social, cultural e linguística que diferenciam mulheres de homens e produzem seus corpos como corpos dotados de sexo, gênero e sexualidade.

Palavras-chave: Mulheres na prisão, mulheres em cárcere, saúde, revisão dialógica.

\begin{abstract}
The significant increase in the incarceration of women in Brazil has had an impact on security policies, penitentiary administration, as well as policies specific to gender inequality. This text is based on the mapping of literature accessed in database and aims to increase the discussion on women's health in the Prison System, focusing on the gender approach that circulates in national and international articles published between 2004 and 2015. To build the object of study, these scientific productions were accessed from the initial survey in the databasesScientific Electronic Library Online (SCIELO); Journals from Coordenação de Aperfeiçoamento de Pessoal de Nível Superior (CAPES) and Virtual Health Library (Biblioteca Virtual em Saúde (BVS))- using the descriptors: women in prison and women in jail. 74 articles were selected, in which the following themes were identified: profile (9), everyday life (22), health (16), family (16), resocialization (11) and media (1); the study fields in which they were produced: Nursing (5), Psychology (15), Public/collective Health (16), Social Work (1), Medicine (10), Social Sciences (10), Law (8), Education (9); regions and countries. The articles were selected by its identification with the health discussion and the subtopics were defined through the summaries of each text and guided by the research objective. In a dialogical review of the literature, it was identified that the productions point to gender differences, without, however, presenting a discussion about any specific gender theory. Most refer to gender as all forms of social, cultural and linguistic construction that differentiate women from men and produce their bodies as bodies endowed with sex, gender and sexuality.
\end{abstract}

Keywords: Women in prison, Women in jail, Health, Dialogical review. 


\section{INTRODUÇÃO}

Os sistemas punitivos são respaldados em uma lógica de confinamento em massa, reflexo de uma construção histórica, em que a solução da criminalidade está ligada diretamente a construção de presídios e a privação de liberdade como pena. O sistema prisional é pensado como um mecanismo de adestramento social daqueles sujeitos que possuem alguma conduta desviante, uma vez que seu objetivo é torna-los apto ao convívio em sociedade, sem garantir, entretanto, as condições dignas para o fomento dessa recuperação. Esta realidade é ainda mais intensa quando tratamos do cárcere feminino, isto porque a construção social existente sobre os papéis destinados aos homens e às mulheres é reproduzida, de forma ainda mais perversa, no sistema prisional (Barcinski \& Cúnico, 2014).

Um panorama sobre a população carcerária feminina, no Brasil, é apresentado em 2010, pelo Departamento Penitenciário Nacional (DPN). Trata-se do primeiro a trazer dados sobre a situação das mulheres no sistema prisional, os estabelecimentos $e$ as peculiaridades do cárcere feminino. Entre os números apresentados, encontra-se a informação do crescimento de $261 \%$ das mulheres encarceradas, entre 2000 e 2010, enquanto a população masculina teve um aumento de 106\% no mesmo período (Brasil, 2014).

O relatório do Conselho Nacional de Justiça (CNJ), publicado em 2014, descreve o Brasil como a $4^{a}$ maior população prisional do mundo, com um número de presos que ultrapassa os $496.25 \mathrm{mil}$, dos quais $6,6 \%$ correspondem às mulheres. O Brasil está atrás apenas de países como Estados Unidos, que possui uma população de apenados de 2.292.133 mil; China, com 1.650 .000 mil e Rússia, com 806.100 mil (Brasil, 2014).

O Levantamento Nacional de Informações Penitenciárias (INFOPEN) sistematizou, também em 2014 , as informações disponíveis sobre as mulheres encarceradas no Brasil, destacando que a população feminina subiu de 5.601 para 37.380 detentas entre 2000 e 2014 , totalizando um crescimento de $567 \%$ em 14 anos. A taxa de mulheres presas no país é superior ao crescimento geral da população carcerária, que teve aumento de $119 \%$ no mesmo período (Brasil, 2014).
No que se refere aos estabelecimentos prisionais, a maior parte é voltada exclusivamente ao público masculino, cerca de $75 \%$. Apenas $7 \%$ são voltadas ao público feminino e outros $17 \%$ são mistos, no sentido de que podem ter uma sala ou ala específica para mulheres dentro de um estabelecimento anteriormente masculino. Menos da metade dos estabelecimentos femininos dispõe de cela ou dormitório adequado para gestantes (34\%). Nos estabelecimentos mistos, apenas $6 \%$ das unidades dispunham de espaço específico para a custódia de gestantes e lactantes (Brasil, 2014). Essas informações sinalizam que, as masculinidades ainda tem sido demarcada como regra para o contexto prisional, com prevalência de serviços e políticas penais direcionados para homens, negligenciando as diversidades que compreendem a realidade prisional feminina.

É apenas em 2014, que se constitui, no Brasil, a Política Nacional de Atenção às Mulheres em Situação de Privação de Liberdade e Egressas do Sistema Prisional (PNAMPE). Essa política amplia - olhar sobre a população prisional feminina, pois inclui, dentre outras ações, a prevenção de todos os tipos de violência contra essas mulheres. Abrange ainda o fomento à adoção de normas e procedimentos de saúde no cárcere adequados às especificidades das mulheres às questões de gênero, idade, etnia, cor ou raça, sexualidade, orientação sexual, nacionalidade, escolaridade, maternidade, religiosidade, deficiências física e mental e outros aspectos relevantes, bem como o incentivo à construção e adaptação de unidades prisionais para o público feminino (Brasil, 2014b).

Não obstante, é fundamental considerar, que o Plano Nacional de Saúde no Sistema Penitenciário (PNSSP) foi lançado em 2003, tendo como objetivo contribuir para o controle e/ou a redução dos agravos de saúde mais frequentes na população penitenciária do país, bem como trabalhar na lógica da prevenção e da promoção em saúde. Entretanto, em relação às especificidades do cárcere feminino, o PNSSP prevê preferencialmente ações voltadas à saúde maternoinfantil, ao pré-natal e puerpério e, a efetivação de tais ações não está garantida. As mulheres, dentro do sistema penitenciário, recebem maior atenção em saúde, quando estão grávidas ou vinculadas a uma criança (Lermen, Cúnico, \& Jesus, 2015). 
Em 2017, o relatório MulhereSemPrisão, que foi construído a partir do estudo de processos judiciais e entrevistas com mulheres encarceradas, apresenta e amplia o debate e o campo de visão dos membros do sistema de justiça, por meio da própria voz das mulheres. Seu objetivo é fortalecer ações que possam concretizar a redução do aprisionamento de mulheres (ITTC, 2017). De acordo com esse relatório, as mulheres presas são as principais responsáveis pelos cuidados dos filhos ou de outros parentes, ou seja, quando uma mulher é presa, a família toda é impactada, desestruturando o orçamento familiar e também a vida de todos aqueles que dependiam de seus cuidados. Quando um homem é preso, a mulher mantém a família do lado de fora.

A organização não governamental Human Rights Watch $(\mathrm{HRW})^{1}$, a maior entidade em defesa dos direitos humanos, em 2017, afirmou que a nova Lei Anti Drogas abre lacunas para uma interpretação subjetiva das autoridades quanto à diferença entre usuárias e traficantes, fazendo com que a população carcerária aumente significativamente. Para a organização, muitas pessoas são presas portando pequenas quantidades de drogas e acabam sendo condenadas e encarceradas como traficantes, principalmente as mulheres. A mudança da Lei Anti Drogas ocorreu no dia 23 de agosto de 2006. Pela nova lei, quem for apanhado transportando, vendendo ou produzindo drogas fica sujeito a uma pena de reclusão que varia de 5 a 15 anos, além de pagar multa de $\mathrm{R} \$ 500$ a $\mathrm{R} \$ 1,5$ mil.

Diante desse cenário, tem crescido significativamente o debate sobre 0 encarceramento de mulheres ao longo dos anos, trazendo impacto para as políticas de segurança, administração penitenciária, assim como para as políticas específicas à desigualdade de gênero. Essa problemática vem chamando a atenção de diversos atores estatais e da sociedade civil, o que tem levado a produção de pesquisas e debates, assim como de dados oficiais sobre essa realidade tradicionalmente negligenciada (Brasil, 2016).

Ao considerar essas informações, buscou-se em um primeiro momento, mapear as produções científicas nacionais e internacionais que abordam a situação das mulheres no Sistema Prisional de 2004 a 2015, para identificar quais os temas abordados, em que regiões e países e em quais áreas de estudo têm sido produzidas. Em um segundo momento, analisa-se as discussões presentes nos artigos acessados, sobre - cuidado em saúde direcionado a essas mulheres, norteadas por uma revisão dialógica da literatura, cujo trabalho foi apresentado no $6^{\circ}$ Congresso lberoAmericano em Investigação Qualitativa e publicado em seus anais (Ribeiro \& de Deus, 2017). Esse estudo inicial, levou ao objetivo deste texto de ampliar a discussão sobre a saúde das mulheres no Sistema Prisional, analisando o recorte de gênero que circula nos artigos selecionados no primeiro momento.

\section{METODOLOGIA}

O objetivo deste estudo de analisar o recorte de gênero é alcançado a partir do levantamento inicial nas bases de dados, do qual resultou na organização e análise das informações veiculadas nas produções científicas selecionadas. No primeiro momento foram classificados e discutidos sobre o que versavam os temas abordados nos artigos sobre o cuidado em saúde direcionado às mulheres no sistema prisional (Ribeiro \& de Deus, 2017).

Neste estudo, foram selecionados os mesmos artigos identificados pela discussão de saúde e focalizados os repertórios linguísticos que apresentam uma diferenciação de gênero para serem analisados. Dessa análise resulta os subtemas, que foram definidos através dos resumos de cada texto e norteados pelo objetivo da pesquisa, que facilita a organização dos assuntos, a problematização e o diálogo entre eles.

\section{Levantamentos na Base de Dados}

O levantamento dos artigos nas bases de dados levou em conta as suas características e pertinência aos objetivos desta pesquisa. Foram as seguintes: Scientific Electronic Library Online (SCIELO) abrange

\footnotetext{
'A Human Rights Watch é uma organização internacional de direitos humanos, não-governamental, sem fins lucrativos. Fundada em 1978 , é reconhecida por investigações sobre violações de direitos humanos, elaboração de relatórios imparciais sobre essas investigações e o uso efetivo dos meios de comunicação para informar e sensibilizar diversos públicos sobre suas causas. Extraído do site: https://www.hrw.org/pt/sobre-human-rights-watch, acessado no dia 12 de fevereiro de 2017.
} 
uma coleção selecionada de periódicos científicos brasileiros; Portal de Periódicos da Coordenação de Aperfeiçoamento de Pessoal de Nível Superior (CAPES), uma biblioteca virtual que reúne e disponibiliza a produção científica internacional, para as instituições de ensino e pesquisa no Brasil e; Biblioteca Virtual em Saúde (BVS) acessível de forma universal pela internet, promove a cooperação técnica em informação e comunicação científica em saúde, produzidas na América Latina e Caribe, compatível com as bases internacionais (Ribeiro, Martins, \& Lima, 2015).

A interação inicial com o tema foi orientada a partir da pesquisa em base de dados, sendo esta a nossa compreensão inicial sobre o campotema pesquisado. Considera-se que as bases de dados não só organizam e veiculam, como também legitimam as informações que armazenam, funcionando, assim, como ferramentas midiáticas da ciência (Ribeiro, Martins, \& Lima, 2015). A busca foi realizada em maio de 2016, utilizando-se como ícones as seguintes palavras-chave: mulheres em cárcere; mulheres na prisão.

Os critérios que delimitaram e orientaram a seleção do material foram: I Parâmetro temático: produções que abordassem ou pesquisassem sobre mulheres na prisão/cárcere, II Parâmetro linguístico: estudos publicados em língua portuguesa, inglês e espanhol; III Parâmetro cronológico de publicação: produções publicadas no período entre 2004 a 2015. Como as bases de dados da CAPES e da BVS não disponibilizam alguns artigos na íntegra, foram mapeados os locais, as datas e o idioma de algumas publicações. O período de 2004 à 2015, delimitado no parâmetro cronológico, teve em vista a mudança da Lei Anti Drogas.

No Scientific Electronic Library Online (SCIELO) por meio das palavras-chave: mulheres em prisão, obteve-se um total de 7 artigos, dos quais foram selecionados 6 e excluídos 1 por não ser compatível com a temática. Enquanto que por meio das palavras chave ..... (seguir como está: mulheres em cárcere, ....)

No Portal de Periódicos da Coordenação de Aperfeiçoamento de Pessoal de Nível Superior (CAPES) chegou-se a um total de 55 artigos/teses/ dissertações, a partir das palavras-chave mulheres na prisão. Foram selecionados 29 e excluídos 6 repetidos, 18 fora do tema proposto, um por falta de acesso e um produzido fora do tempo demarcado neste trabalho.

No Portal de Periódicos da Coordenação de Aperfeiçoamento de Pessoal de Nível Superior (CAPES), usando as palavras-chave mulheres em cárcere, foram encontrados 21 artigos/teses/dissertações, mas selecionados apenas 5, pois 10 eram repetidos e 6 não correspondiam ao tema proposto.

Na Biblioteca Virtual em Saúde (BVS) foram acessados 120 artigos/teses/dissertações, na busca com as palavras-chave mulheres na prisão e considerados apenas 15. Foram desconsiderados 25 repetidos, 73 fora do tema proposto, 2 sem acesso e 5 fora do tempo delimitado.

Na Biblioteca Virtual em Saúde (BVS), usando as palavras-chave mulheres em cárcere, foram acessados 113 artigos/teses/dissertações, selecionados 14, rejeitados 37 repetidos, 49 fora do tema, $8 \mathrm{sem}$ acesso e 5 fora do tempo delimitado.

Tabela 01. Número de produçães científicas nacionais e internacionais sobre mulheres na prisão/cárcere por fonte e descritores. Maceió, 2016.

\begin{tabular}{|c|c|c|c|c|}
\hline \multirow{3}{*}{ Fonte } & Descritores & $\begin{array}{c}\text { Produções } \\
\text { Encontradas }\end{array}$ & $\begin{array}{c}\text { Produções } \\
\text { Excluídas }\end{array}$ & $\begin{array}{c}\text { Produções } \\
\text { Finais }\end{array}$ \\
\hline \multirow{3}{*}{ SCIELO } & Mulheres na prisão & 7 & 1 & 6 \\
\cline { 2 - 5 } & Mulheres em cárcere & 7 & 2 & 5 \\
\cline { 2 - 5 } & Total & 14 & $\mathbf{3}$ & 11 \\
\hline \multirow{2}{*}{ BVS } & Mulheres na prisão & 120 & 105 & 15 \\
\cline { 2 - 5 } & Mulheres em cárcere & 113 & 99 & 14 \\
\cline { 2 - 5 } & Total & $\mathbf{2 3 3}$ & $\mathbf{2 0 5}$ & $\mathbf{2 9}$ \\
\hline Portal de & Mulheres na prisão & 55 & 26 & 29 \\
\cline { 2 - 5 } $\begin{array}{c}\text { Periódicos } \\
\text { CAPES }\end{array}$ & Mulheres em cárcere & 21 & 16 & 05 \\
\cline { 2 - 5 } & Total & $\mathbf{7 6}$ & $\mathbf{4 2}$ & $\mathbf{3 4}$ \\
\hline Total Geral & \multicolumn{2}{|c}{} \\
\hline
\end{tabular}

Fonte: Autoras, 2016. 
De acordo com a tabela 1 podemos identificar um grande número de exclusões realizadas inicialmente a partir da leitura dos resumos dos artigos, dissertações e teses, considerando que, apesar de terem sido identificados a partir das bases de dados, não tinham relação com o tema e com os objetivos deste trabalho. Os critérios de exclusão utilizados nessa análise foram: I - artigos repetidos (por terem sido indexados com os dois descritores), II - pesquisas com outros sujeitos (homens, ministério público e psicólogas), III - trabalhos enfocando outros temas (prisão de ventre e prisão colonial) e IV - artigos indisponíveis.

\section{Organização e Análise das Informações}

Para realizar a organização e análise das informações das produções científicas acessadas, sobre a situação das mulheres no sistema prisional, foi adotada a revisão da literatura dialógica, proposta por Sharon Walker (2015). Além disso, foi considerada a influência das discussões de Montuori (2005), que propõe revisões de literatura, norteadas pela perspectiva construcionista, que problematiza a tendência meramente reprodutiva presente nelas. A revisão de literatura é abordada como uma investigação criativa, fruto do processo de inserção e participação do revisor dentro de uma comunidade científica, a partir do seu diálogo com aqueles que a compõe (Montuori, 2005). Essa concepção é ampliada por Walker (2015), ao discutir que cada texto fala com outros, como numa interanimação dialógica.

A característica de revisões dialógicas não é sumarizar os pensamentos e as descobertas de outros e, sim, entrar em diálogo com os enunciados escritos sobre o tema. $O$ que os textos têm em comum? Quais são as aproximações e quais os distanciamentos? Como os textos dialogam com o pesquisador? São questões propostas na revisão dialógica (Walker, 2015).

É nesse contexto relacional que conduzimos essa revisão de literatura, montando conexões, explorando os padrões e interações entre os textos, ressaltando que foram organizados inicialmente a partir da "conversa" das pesquisadoras com eles para, depois, considerar como podem dialogar entre si. Apresenta-se assim, as opiniões críticas de diversos trabalhos, criando uma espécie de debate, discussão e disputa em relação à situação das mulheres no sistema prisional. Fazendo isso, busca-se aumentar o número de vozes e posições diferentes sobre uma mesma temática, atentando-se para o fato de que há diferentes versões sobre o tema e não a busca de uma verdade.

Essas considerações sobre a revisão da literatura dialógica, apoiam-se no referencial teóricometodológico das Práticas Discursivas e Produção de Sentidos, fundamentado na perspectiva do Construcionismo Social (Spink, 2004). Nesse referencial teórico, os repertórios linguísticos constituem-se um dos focos de análise, que se definem como os termos, os conceitos, os lugares comuns e figuras de linguagem que possibilitam as inúmeras construções de sentidos (Spink, 2004).

Dessa forma, procura-se compreender alguns aspectos do conhecimento construído sobre as mulheres no sistema prisional, a partir da análise dos repertórios. Eles podem ser analisados por diversos enfoques, dependendo do objetivo da pesquisa.

A análise das práticas discursivas busca investigar - caráter performático da linguagem em uso, pois quando falamos, estamos invariavelmente produzindo ações, acusando, perguntando, justificando, produzindo um jogo de posicionamentos com nossos interlocutores, tenhamos ou não essa intenção (Spink \& Medrado, 2013). A produção de sentidos não é uma prática individual ou psíquica, mas sim social e dialógica, podendo ser compreendida como um fenômeno sociolinguístico, porque é a linguagem que sustenta as práticas sociais que geram os sentidos. Esses só podem ser compreendidos considerando ○ contexto sócio, cultural e histórico da sua produção.

Esses pressupostos teórico-metodológicos norteiam as discussões sobre as relações e verdades estabelecidas, que atravessam as construções sobre as mulheres no sistema prisional. Tendo em vista que os discursos se caracterizam pelo uso da linguagem institucionalizada, que ocorrem por meio de mecanismos políticos, culturais, de pequenos grupos e ao redor de temáticas específicas, tal como gênero e classe. 


\section{RESULTADOS}

A partir da leitura dos resumos dos trabalhos classificamos as produções acadêmicas segundo eixos temáticos, ano de publicação e área do conhecimento. Os temas foram organizados na tabela 2, que apresenta a quantidade de produções científicas nacionais e internacionais por eixos temáticos.

Tabela 02. Quantidade de produções científicas nacionais e internacionais sobre mulheres presas/cárceres por eixos temáticos. Maceió, 2016.

\begin{tabular}{|c|c|c|c|c|c|}
\hline \multicolumn{7}{|c|}{ Resultado da Pesquisa por Eixos Temáticos } \\
\hline Perfil & Cotidiano & Saúde & $\begin{array}{c}\text { Família e Relações } \\
\text { Afetivas }\end{array}$ & $\begin{array}{c}\text { Contexto } \\
\text { Ressocializaçãó }\end{array}$ & Midiático \\
\hline 8 & 22 & 16 & 16 & 11 & 01 \\
\hline
\end{tabular}

Fonte: Autoras, 2016.

Essa tabela indica que o interesse pela temática sobre mulheres na prisão/cárcere, no contexto acadêmico tem se desenvolvido com maior quantidade de publicações relacionadas ao cotidiano das mulheres no sistema prisional. Apresentamos a seguir a tabela 3 referente à quantidade de produções científicas sobre as mulheres no sistema prisional no decorrer desses 12 anos.

Tabela 03. Quantidade de produções científicas: nacionais e internacionais sobre mulheres presas/cárceres por ano de publicação. Maceió, 2016.

\begin{tabular}{|c|c|c|c|c|c|c|c|c|c|c|c|}
\hline 2004 & 2005 & 2006 & 2007 & 2008 & 2009 & 2010 & 2011 & 2012 & 2013 & 2014 & 2015 \\
\hline 1 & 4 & 7 & 2 & 4 & 3 & 4 & 6 & 9 & 12 & 12 & 10 \\
\hline
\end{tabular}

Fonte: Autoras, 2016.

Em relação à tabela 3 , observamos que as publicações começam a aumentar a partir de 2012 e os anos que se destacam são: 2006; 2013, 2014 e 2015. Alguns fatores podem ser considerados como incidentes críticos para o aumento da produção acadêmica sobre essa temática. As publicações científicas de 2006 podem ter sido incrementadas pela influência das pesquisas e relatórios divulgados naquela época, além da mudança da Lei Anti Drogas, ocorrida no mesmo ano. Ainda podemos observar, nesse quadro, um grande número de estudos publicados entre 2012 e 2015, levando a considerar que o crescimento de $42 \%$ da população prisional feminina, entre os anos de 2007 e 2012, influencia o aumento das publicações nesse período.
Os estudos realizados sobre as mulheres presas/ cárcere têm sido produzidos em sua maioria nos estados do Sul (19) e Sudeste (25) do Brasil, sobressaindo-se no Rio Grande do Sul (16) e em São Paulo (16). Enquanto nas outras regiões; Centro-oeste (4), Norte (2) e Nordeste (10), em menor números, totalizando 60 (sessenta) artigos brasileiros selecionados. Em relação às produções internacionais, um total de 14 (catorze) foram identificadas sobre as mulheres em cárcere, das quais 3 (três) foram produzidas nos Estados Unidos, especificamente na Califórnia, além de na Colômbia (3), Portugal (2), Inglaterra (2), Espanha (2), Indonésia (1) e Chile (1). Identificamos, também, quais as áreas de conhecimento que mais discutiram a situação das mulheres na prisão/cárcere. 
Tabela 04. Quantidade de produções científicas naçionais e internacionais sobre mulheres presas/cárceres por área de conhecimento. Maceió, 2016.

\begin{tabular}{|c|c|}
\hline Saúde Pública/Coletiva & 16 \\
\hline Psicologia & 15 \\
\hline Medicina & 10 \\
\hline Ciências Sociais & 10 \\
\hline Educação & 09 \\
\hline Direito & 08 \\
\hline Enfermagem & 05 \\
\hline Serviço Social & 01 \\
\hline
\end{tabular}

Fonte: Autoras, 2016.

A tabela 4 sinaliza que as áreas de conhecimento da Saúde Pública/Coletiva e da Psicologia são as que predominam entre as pesquisas sobre as mulheres na prisão ou cárcere. A análise dos repertórios linguísticos dos resumos de 16 artigos identificados como relacionados à saúde resultou nos seguintes eixos temáticos: saúde sexual e reprodutiva e direito reprodutivo e sexual; aceso aos serviços de saúde; saúde mental: direito e religião; saúde mental e o uso e abuso de drogas; diferenças de gênero e exclusão social.

A seguir, apresentamos a discussão dialógica com os enunciados presentes nas produções sobre o perfil e nos eixos temáticos, refletindo sobre quem são essas mulheres que estão no sistema prisional e quais discussões de gênero estão presentes nos artigos categorizados como de saúde.

\section{DISCUSSÃO}

As pesquisas de uma forma geral trazem o perfil das mulheres em cárcere, que se aproxima com a literatura voltada exclusivamente para descrevêlas. Os artigos científicos, que têm esse objetivo, descrevem as mulheres presas como jovem, mãe solteira, não branca, condenada por envolvimento com tráfico de drogas (ou entorpecentes), a maioria delas ocupa uma posição coadjuvante no crime, realizando serviços de transporte de drogas e pequeno comércio; muitas são usuárias, sendo poucas as que exercem atividades de gerência do tráfico. Apresentam rupturas de vínculos da vida social em várias dimensões e, na maioria dos casos, possuem apenas 0 ensino fundamental completo. (Lima, 2006); (Guedes, 2006); (Carvalho, Valente,
Assis, \& Vasconcelos, 2006); (Mello, 2008); (Scherer, Scherer, Nascimento, \& Ragozo, 2011 ); (Nicolau et al., 2012); (Oliveira, Costa, Medeiros, \& Cavalcanti, 2013); (Cortina, 2015).

O objetivo deste trabalho é ampliar a discussão sobre a saúde das mulheres no Sistema Prisional, focalizando o recorte de gênero que circula nos artigos nacionais e internacionais publicados entre 2004 e 2015. Para tal, a política nacional de atenção integral à saúde das pessoas privadas de liberdade no sistema prisional e a política de atenção básica, no que se refere às diretrizes sobre saúde sexual e direitos reprodutivos são utilizadas como contrapontos, para a análise dos repertórios linguísticos que circulam nos artigos descritos nos diversos temas identificados.

\section{Saúde sexual e reprodutiva e direitos reprodutivos e sexuais}

Esse subtema é norteado por uma diferenciação entre direitos reprodutivos e sexuais e saúde sexual e reprodutiva. A saúde sexual se define como as várias possibilidades de pensar, sentir e viver a sexualidade, conceito que começa a ser elaborado na década de 90, sob o impacto do HIV/Aids, (Brasil, 2013). Enquanto que a saúde reprodutiva implica que as pessoas possam ter uma vida sexual segura e satisfatória, tendo autonomia para reproduzir e liberdade de decidir sobre quando e quantas vezes deve fazê-lo.

Em consonância com essas definições, o conceito de direitos reprodutivos consiste no reconhecimento do direito básico de todo casal e de todo indivíduo de decidir livre e responsavelmente sobre o número, o espaçamento e a oportunidade de ter filhos e 
de ter a informação e o direito de assim o fazer (Brasil, 2013). Dessa maneira, a ideia de direitos sexuais envolve a aceitação dos diferentes tipos de expressão sexual, a autonomia para tomar decisões sobre o uso do próprio corpo e a igualdade de gênero (Brasil, 2013).

Essa perspectiva dos direitos reprodutivos $\mathrm{e}$ sexuais surge a partir dos movimentos feministas e das conferências e tratados internacionais, principalmente Cairo e Beijing, que buscavam visibilizar e discutir as desigualdades presentes entre homens e mulheres em relação à participação nos processos reprodutivos.

No que concerne à saúde sexual e os direitos reprodutivos, o estudo desenvolvido na penitenciária feminina do Estado do Espírito Santo, com 121 mulheres em situação de prisão/cárcere, teve como objetivo investigar as condições de saúde sexual das mulheres em situação prisional e seu perfil sociodemográfico (Miranda, Vargas, \& Viana, 2004). Os resultados apresentam uma média de idade das participantes de 30,2 anos, com média de 4,8 anos de escolaridade. Todas já haviam tido atividade sexual pregressa; a idade média do primeiro coito foi de 15,2 anos, variando de 9 a 27 anos; $28 \%$ apresentavam história de infeções sexualmente transmissível (IST). Doze $(9,9 \%)$ mulheres estavam grávidas no momento da entrevista. História de gravidez na adolescência era frequente entre elas. A maioria não adotava nenhum método contraceptivo e nem fazia uso de preservativos. Laqueadura tubária foi observada em $19,8 \%$ e citologia cervical anormal em $26,9 \%$.

Os problemas apresentados acima dialogam com outra pesquisa sobre as necessidades de anticoncepcionais de mulheres encarceradas, na qual buscou-se determinar as intervenções de controle de natalidade viáveis e eficazes (Hale et al., 2009). A pesquisa foi realizada com 188 mulheres em uma prisão no sudeste dos Estados Unidos e os resultados apresentaram altas taxas de infecções sexualmente transmissiveis (IST) $(50,5 \%)$, uso inconsistente do controle de natalidade $(36,5 \%)$ e uso de métodos de controle de natalidade não confiáveis. A maioria não desejava engravidar no futuro $(61,5 \%)$, mas pretendia fazer sexo após a libertação da prisão $(76,9 \%)$. As mulheres que já tinham filhos eram mais propensas ao controle de natalidade e a proteção contra as IST após a liberação $(77,9 \%)$. Essa pesquisa destaca que as mulheres não brancas eram mais propensas a serem solteiras, a terem mais IST e a usar uma variedade menor de métodos anticoncepcionais do que as mulheres brancas. Em ambos os estudos a discussão sobre os métodos anticoncepcionais não traz nenhuma nomeação de gênero.

Os artigos que discutem os direitos sexuais focalizam suas pesquisas na infecção pelo HIV-AIDS, além de outras infeções e para desigualdades de gênero. Posicionam as mulheres como o grupo mais vulnerável dentro das prisões, que estão relacionadas às suas especificidades como raça e etnia, idade, deficiência, orientação sexual, identidade de gênero, nacionalidade, situação de gestação e maternidade, entre tantas outras nuances.

Entre os artigos estão duas produções brasileiras: uma que aborda o problema da infecção do HIVAids, com o intuito de identificar a prevalência de anti-HCV, anti-HIV e coinfecção HCV/HIV em um presídio feminino do Estado do Rio Grande do Sul - Brasil (Muller, 2008) e, outra que realiza uma revisão sistemática da prevalência de HIV/AIDS e demais Infecções Sexualmente Transmissíveis (IST) na população carcerária feminina no Brasil (Bezerra, 2015).

Em ambos os artigos foi possível identificar que as mulheres encarceradas constituem um grupo de risco vulnerável ao vírus da hepatite C, denominado HCV, HIV e coinfecção HCV/ HIV e que se agravam no contexto prisional, em que a estrutura de encarceramento, de maneira geral, não oferece um atendimento minimamente adequado às especificidades da mulher presa, retratando a desigualdade de gênero que existe no sistema prisional. Entende-se que as pessoas sob tutela do sistema prisional apresentem, devido suas características, maior risco às doenças sexualmente transmissíveis.

Vinculada aos direitos sexuais e reprodutivos, a pesquisa desenvolvida nos Estados Unidos (Kramer \& Comfort, 2011), também inclui a nomeação de gênero ao discutir as estratégias de prevenção do HIV voltadas para as mulheres na prisão. Afirma que essa população específica se encontra em 
vulnerabilidade decorrente do encarceramento, por conta das relações sexuais estabelecidas com homens encarcerados e pela injeção de drogas. Os fatores de risco para as mulheres são em sua maioria de gênero, cerca de $80 \%$ das mulheres com HIV foram infectadas por um parceiro sexual. Poucas são aquelas, comparadas aos homens, que se infectam com o uso de drogas injetáveis. Outra realidade apresentada, refere-se ao desejo delas terem filhos, depois que saem da prisão ou da libertação de seus companheiros. A pressa para engravidarem, faz com que elas não levem em conta os cuidados de saúde, pré-natais, inclusive a prevenção do HIV.

Nesses três artigos observa-se que a maioria das intervenções de prevenção do HIV são dirigidos para os homens, focalizando a prevenção dos riscos em termos mais individuais do que relacionais.

Essa demarcação masculina é discutida nas pesquisas que abordam as dificuldades de acesso às visitas íntimas por parte das mulheres no sistema prisional, como assegura a Lei de Execução Penal (Projeto de lei n. ${ }^{\circ} 5.075$ de 2001). Em 27/12/2001 a resolução $n^{\circ} .96$ da Secretaria das Administrações Prisionais regulamentou o exercício da visita íntima às mulheres presas assegurando este direito, prescrevendo igualdade de gênero já previsto na Constituição federal. No entanto, é notório que há uma dificuldade por parte das mulheres de conseguirem autorização dos gestores desses estabelecimentos e por precisarem se adequar aos critérios para a realização dessas visitas, tais como: serem casadas no civil e heterossexuais, o que não acontece quando as visitas são direcionadas aos homens (Lima, 2006).

Uma das pesquisas busca compreender os significados da visita íntima, na perspectiva da mulher presa, como também, caracterizar o seu perfil na Penitenciária Feminina da Capital de São Paulo (PFC), do ponto de vista sóciodemográfico, prisional e familiar/conjugal (Lima, 2006). Foram consultados 655 prontuários das mulheres e realizados dois grupos focais, um com mulheres que optaram pela visita íntima e outro com as que não optaram, cada grupo formado por 06 à 09 participantes. Os resultados apresentados nos grupos focais relatam o constrangimento e a humilhação, no contexto da visita íntima, que são modelados pelo interesse na manutenção da conjugalidade, pela necessidade de satisfazer o parceiro ou como modo de afirmar a liberdade sexual através da recusa à visita íntima, por exemplo. Somente $2,6 \%$ das mulheres referiram, nos prontuários, ter o desejo em inscrever o parceiro para a visita íntima.

A pesquisa realizada na penitenciária feminina do Ceará, com 155 participante, investiga o perfil socioeconômico e sexual das presidiárias (Nicolau et al., 2012), que correspondem às características descritas anteriormente. Os resultados apresentados revelam que a primeira relação sexual foi precoce, pouca variedade de parceiros sexuais, usar drogas e possuir tatuagens/piercings representaram aspectos comuns às participantes e suas parcerias. A homo/bissexualidade e a prostituição estiveram fortemente presentes. As IST antes ou após a prisão apresentaram pouca expressividade. Conclui que a garantia da visita íntima e a realização de exames preventivos ainda enfrentam grandes entraves no sistema prisional. A visita íntima denuncia o controle frente à sexualidade das mulheres presas e a restrição no desenvolvimento e manutenção dos vínculos afetivos que restou a estas mulheres.

\section{Acesso aos serviços de saúde}

A discussão desse subtema é norteada pela política nacional de atenção integral à saúde das pessoas privadas de liberdade (PNAISP) no sistema prisional. Essa política tem como objetivo garantir o acesso ao cuidado integral no Sistema Único de Saúde (SUS). Prevê que os serviços de saúde no sistema prisional passem a fazer parte da rede de atenção à saúde (RAS) do SUS, qualificando também a atenção básica no âmbito prisional como porta de entrada do sistema e ordenadora das ações e serviços de saúde pela rede. Estabelece assim, o acesso da população penitenciária a ações e serviços de saúde, tais como: instalações adequadas para gestantes e presas que deram à luz recentemente; manutenção de creches para acolher crianças maiores de seis meses e menores de sete anos e que as unidades prisionais sejam compostas apenas de agentes penitenciárias do sexo feminino (Brasil, 2014b).

Os direitos específicos garantidos a essas mulheres na PNAISP, restringem-se ao controle do câncer 
cérvico-uterino e de mama, doenças sexualmente transmissíveis e à saúde materno infantil; logo não partem de uma perspectiva de saúde integral das mulheres que dê conta do bem estar para além de um estado de não doença.

Entre as produções que discutem a diferenciação de gênero no acesso aos serviços de saúde, identificase um estudo desenvolvido na Colômbia, com 170 mulheres em situação de prisão/cárcere, que tem o objetivo de caracterizar as condições de acessibilidade aos serviços de saúde das internas e de seus filhos, que convivem no centro de reclusão em Buen Pastor de Medellín (Mery, Pacheco \& López, 2011). Os resultados apresentam que, embora elas tenham algum tipo de acesso aos serviços de saúde, manifestavam um alto grau de insatisfação, principalmente pela demora na atenção, insuficiência de recursos e dificuldades nas tramitações administrativas em garantir os cuidados em saúde para as mulheres e seus filhos. Concluiu-se que há a necessidade de efetivação das políticas públicas de saúde direcionadas às mulheres presas, assim como se ressalta a importância de uma equipe multidisciplinar comprometida com a assistência em saúde.

Também inclui a iniquidade de gênero no acesso aos serviços de saúde, a pesquisa realizada pelo departamento de saúde pública da universidade de Oxford, no Reino Unido, envolvendo 37 detentas, que teve o objetivo de explorar os cuidados primários em saúde fornecido às mulheres na prisão, fazendo parte de um projeto mais amplo, voltado para o impacto da prisão na saúde dessas mulheres (Plugge, Douglas, \& Fitzpatrick, 2008). Os resultados apresentados revelam contradição na percepção dessas mulheres sobre os cuidados recebidos, pois houveram relatos que consideravam um cuidado de qualidade, nos quais os médicos eram qualificados e respeitosos, enquanto que outras percebiam uma precária qualidade na assistência em saúde. Aquelas que criticavam o serviço se queixaram de uma dificuldade de acesso aos cuidados e à medicação, bem como tratamento desrespeitoso e quebra de sigilo por parte da equipe.

Os pesquisadores levam em conta os limites da pesquisa, cujo resultados são parciais e localizados, representando um momento histórico particular, não podendo ser generalizada para outros espaços. Sinalizam que na Inglaterra e no país de Gales, no período de 2008, estava acontecendo uma mudança na política de cuidados em saúde no sistema prisional. Entretanto, concluem que o relato das mulheres prisioneiras sugere que há uma lacuna entre as experiências dessas mulheres e as aspirações da política pública (Plugge, Douglas, \& Fitzpatrick, 2008).

Essas pesquisas indicam que embora essas mulheres tenham algum tipo de acesso aos serviços de saúde, estes são caracterizados por não focalizarem a sexualidade feminina, suas demandas e especificidades advindas das questões de gênero. $O$ conceito de gênero que permeia esses estudos sinaliza que as mulheres e suas filhas (os), reclusas no sistema prisional, são as mais penalizadas com o sucateamento de serviços e políticas sociais, dentre outros problemas. Os programas e as políticas voltadas a população prisional aparentemente não incorpora a categoria de gênero no planejamento das ações de saúde que objetiva promover uma melhoria nas condições de vida das presidiárias e de suas filhas (os).

As discussões de gênero trazida nessas pesquisas reflete a construção binária das categorias masculina e feminina através de conceitos e valores culturais sobre os corpos e a sexualidade. Sendo as masculinidades demarcadas como regra para o contexto prisional, com prevalência de serviços e políticas penais direcionados para homens, deixando em segundo plano as especificidades que compreendem a realidade prisional feminina. Não obstante, reconhecemos que as pesquisas não trazem a discussão sobre a saúde dos homens no sistema prisional, contudo, é necessário problematizar como esse marcador, as masculinidades, define, a priori, 0 acesso à saúde no sistema prisional.

\section{Saúde Mental: Direito e Religião}

A saúde mental dentro do sistema prisional é um problema de saúde pública e de segurança, constituindo-se como um dos crescentes desafios para as autoridades que trabalham com políticas públicas na área prisional.

No que concerne à saúde mental, identificamos pesquisas que apresentam diferenciação entre 
homens e mulheres quanto aos aspectos que envolvem o suicídio e os fatores adversos vivenciados na infância. Outros estudos realizados com mulheres em cárceres trazem a saúde mental como resultado de suas análises sobre o direito à saúde.

A pesquisa desenvolvida nas prisões e cadeias adstritas ao Instituto Nacional Penitenciário e de Prisões da Colômbia (INPEC), com 60 internos, sendo que $68,3 \%$ eram homens e $31,7 \%$ eram mulheres, teve como objetivo estabelecer quais das variáveis de tempo, modo e local, típicas do contexto prisional aparecem mais frequentemente em 60 presos envolvidos com pensamentos de suicídio, tentativa de suicídio e suicídio consumado durante o primeiro trimestre de 2013 (Castillo, Cifuentes, Briceño \& Noriega, 2014). Os resultados verificaram que a tentativa de suicídio, cerca de $76,7 \%$, é o comportamento que mais ocorre no espaço prisional, estabelecendo a existência de relações estatisticamente significativas entre o tipo de comportamento suicida e gênero, gênero e método utilizado, o local do evento e o tipo de comportamento suicida. Foi constatado que nos primeiros dias de aprisionamento existe maior probabilidade de tentativas de suicídio por parte das mulheres em situação de prisão/cárcere $(41.7 \%)$. Esses dados podem ser associados ao desequilíbrio emocional e afetivo, que fragmenta a vida habitual da mulher, pelo encarceramento.

O estudo realizado em estabelecimentos prisionais do norte de Portugal, com 42 mulheres e 65 homens institucionalizados, também faz comparações do estado de saúde entre homens e mulheres ao ter como objetivo conhecer as diferenças entre sexos, no que diz respeito às variáveis de adversidade na infância, comportamentos de risco para a saúde da população reclusa e as dimensões psicopatológicas, no sentido de adequar estratégias de intervenção em contexto prisional, averiguando as diferenças entre homens e as mulheres reclusas (Alves, Dutra, \& Maia, 2013). Os resultados apresentaram uma média de adversidade total de 5.05 ( $D P=2.63$ ) para as mulheres e de 2.63 (DP $=2.18$ ) para os homens, sendo a prevalência significativamente mais elevada junto da população feminina $(Z=$ -4.33; $p=.000)$. Sugerem também uma elevada prevalência de comportamentos de risco e de sintomatologia psicopatológica em ambos os grupos, sendo esta última superior nas mulheres. Os relatos de abuso físico, emocional, sexual, bem como negligência e disfunção familiar durante a infância são relatados, em sua maioria, mais pelas mulheres do que pelos homens. As diferenças entre sexos são mais notórias nos relatos de adversidade na infância e à sintomatologia psicológica, porém também existem diferenças nos comportamentos de risco para a saúde, essencialmente em relação aos comportamentos sexuais de risco.

Quanto ao direito à saúde, a pesquisa desenvolvida na Casa de Reeducação Maria Júlia Maranhão, localizada no Complexo Penitenciário de Mangabeira na cidade de João Pessoa-Paraíba, cujo objetivo é investigar como está o sistema carcerário em nosso país atualmente, os resultados mostraram que $\circ$ ambiente carcerário causa danos significativos à saúde mental das mulheres, sendo necessário que este ambiente torne-se um espaço mais salubre, mas também, um lugar de aprendizagem, profissionalização, recuperação e ressocialização dessas pessoas (Lima, 2005).

Outro estudo que discute a relação entre direito e saúde foi construído a partir de três estudos originais. O primeiro traz uma análise das principais bases documentais que regem a saúde nas prisões no Brasil. O segundo é uma leitura sobre a saúde mental de mulheres que vivem no cárcere com ênfase para as formas de resiliência que se apresentam durante o cumprimento da pena privativa de liberdade. A terceira pesquisa traz uma análise dos determinantes sociais de saúde presentes na vida no cárcere com destaque para o quadro de superlotação prisional na instituição. Para tanto, a pesquisa objetivou conhecer e analisar as condições de vida e saúde de mulheres em uma prisão do Estado da Paraíba (Lima, 2013). Os resultados demonstraram que as privações das mulheres que ali vivem estão muito além da pena privativa de liberdade. $O$ direito à saúde e as condições dignas de cumprimento da pena não estão sendo garantidos pelo Estado. Isto sugere o atual descumprimento do papel do Estado enquanto detentor das vidas presentes nas prisões brasileiras.

Vinculada a saúde mental e religião, um artigo focaliza sua pesquisa na possibilidade da religião favorecer a reabilitação em saúde mental. A pesquisa é desenvolvida na penitenciária feminina de São 
Paulo, com 358 mulheres, que teve como objetivo verificar o perfil de saúde mental e a relação entre religião, religiosidade e saúde mental (Costivelli \& Dalgalarrondo, 2006). Os resultados descrevem que uma maior religiosidade pessoal associou-se a menor frequência de possível transtorno mental, contudo, poucos estudos no Brasil abordaram a saúde mental em população carcerária feminina e a sua relação com a religiosidade, apesar da religião ter um importante papel na vida de indivíduos encarcerados. Não foram encontrados dados sugestivos de que a religiosidade pudesse evitar o envolvimento com a criminalidade. Assim a suposição de que a presença maciça de igrejas pentecostais e neopentecostais inibe comportamentos criminosos não foi evidenciada empiricamente nesta pesquisa.

As discussões de gênero que permeiam a construção dessas pesquisas, compreende que as mulheres sofrem duplamente com as consequências dos transtornos mentais, dadas as condições insalubres, de abuso, de negligencia e de isolamento que caracterizam o encarceramento e que são fonte de tensão e mal-estar psíquico-físico. Essas condições são acentuadas pela desigualdade de gênero tão arraigada na sociedade e que se apresentam de forma mais perversa no sistema prisional. De acordo com o relatório MulherSemPrisão (2017), as mulheres presas são as principais responsáveis pelos cuidados de filhos ou de outros parentes, o encarceramento desestrutura o orçamento familiar e também a vida de todos aqueles que dependiam de seus cuidados. Esses aspectos são agravantes à situação de saúde mental. As pesquisas não sinalizam nenhuma teoria de gênero específica, compreendendo esse conceito a partir do binarismo homem e mulher.

\section{Saúde mental e o uso e abuso de drogas}

Em relação ao uso e abuso de drogas foi localizado apenas um artigo que relaciona 0 uso abusivo de drogas com $\circ$ risco para $\circ$ desenvolvimento de transtorno de estresse pós-traumático (TEPT). Essa pesquisa foi realizada pelo Núcleo de Ciências Comportamentais e do Desenvolvimento (NCCD), pelo departamento de farmacologia e fisiologia e, por fim, pelo Instituto Biomédico da Universidade Federal Fluminense. O seu objetivo é determinar a frequência de TEPT entre 134 mulheres encarceradas, no Rio de Janeiro, e sua relação com $\circ$ uso de drogas na prisão (Quitete, Paulino, Hauck, Nemer, \& Fonseca, 2012). Apesar de estar em regime prisional, o uso de drogas ilícitas é bastante comum entre as mulheres presas, cerca de $53 \%$ das entrevistadas relatam o uso, porém, - Estado não reconhece a existência de drogas nas unidades prisionais. As mulheres foram também avaliadas para a determinação de ansiedadetraço, depressão, eventos estressores, características sociodemográficas e comparadas quanto à presença ou não do transtorno.

Os critérios utilizados nessa pesquisa foram determinados pelo DSM-IV, o Inventário Christo para descrição de uso de drogas, o Inventário de Ansiedade Traço-Estado e o Inventário Beck para avaliação de sintomas de ansiedade e depressão, respectivamente. Os resultados demonstraram uma alta prevalência de TEPT entre as participantes. Das 134 mulheres avaliadas, $40,3 \%$ apresentaram TEPT, consta também que a causa mais comum de TEPT em mulheres é a violência sexual ou abuso físico quando crianças. Apesar de todas as entrevistadas estarem encarceradas, a prisão não foi considerada um evento traumático por $27,6 \%$ das detentas. Apontam também que essas mulheres não possuem privacidade, lazer, raramente recebem visitas e estão afastadas de seus filhos, a presença de ansiedade e depressão, principalmente entre as participantes TEPT-positivas, favorece o uso de cocaína, calmantes e nicotina, tendo em vista que todas as TEPT-positivas apresentavam algum grau de depressão em comparação às TEPT-negativas ( $p<0,05$ ) (Quitete et al., 2012). Quanto ao risco de suicídio, cerca de um em cada três participantes deste estudo referiu pelo menos uma tentativa.

As discussões que permeiam esse artigo articulam a perspectiva de que a saúde mental dessas mulheres é, em parte, determinada por questões de gênero, somadas às condições socioeconômicas e culturais. As produções científicas que envolve essas discussões não limitam suas análises aos estudos sobre mulheres, mas problematizam as relações de poder existentes entre homens e mulheres. As questões de gênero que colaboram para que as mulheres sejam as principais vítimas do transtorno de estresse pós traumático, como apresenta a pesquisa, é construída em diálogo com as múltiplas violências que formam a trajetória de parte da população feminina. 


\section{Diferenças de gênero e exclusão social}

O estudo que focaliza algumas características particulares de manifestações do processo de exclusão social segundo gênero (Carvalho et al., 2006) está inserido numa pesquisa realizada em 1998, pela Coordenação de Saúde do Departamento de Sistema Penitenciário (Desipe) da então, Secretaria de Estado de Justiça do Rio de Janeiro, com o apoio do Ministério da Saúde. Foram entrevistados 2.039 presos por estudo seccional, e utilizada a razão de prevalência como medida de associação entre sexo e as demais variáveis, tais como: a descrição do perfil da população carcerária quanto a aspectos sociodemográficos, história penal, uso de drogas e doenças sexualmente transmissíveis. A análise multivariada, através de regressão logística foi utilizada, em uma segunda fase, na explicação de um efeito conjunto das variáveis independentes sobre a variável sexo.

Os resultados apresentados revelam que a descrição do perfil dessa população correspondem às características descritas anteriormente. $O$ modelo final foi construído a partir das variáveis que apresentaram poder de explicação nas diferenças observadas entre a população prisional do sexo masculino e feminino. Os fatores que se mostraram, de modo isolado, mais fortemente associados ao sexo masculino na prisão foram: receber visita íntima, estar preso por sete anos ou mais, ser casado, estar condenado no artigo 157 (Roubo) do Código Penal, ter ainda três anos ou mais a cumprir de pena e ter feito uso de maconha antes de ser preso. Já, para $\circ$ sexo feminino, os fatores mais importantes foram: ter doença sexualmente transmissível antes da prisão (tricomoníase, candidíase e sífilis) e na prisão (candidíase), ser viúva, estrangeira, usar tranquilizante na prisão, ter visitado alguém na prisão antes de ser presa e ter 35 anos ou mais. O fato das mulheres terem visitado alguém na prisão com mais frequência que os homens pode ser devido ao estímulo que a mulher recebe para desempenhar o papel social de "cuidadora" que the é destinado. Além disso, não se pode desconsiderar que as mulheres presas estão imersas em histórias de violência, tanto sob o ponto de vista da experiência individual, quanto em relação aos parentes próximos.
Essa pesquisa caracteriza a diferença de gênero, buscando definir as características da população prisional, identificando quem são os excluídos socialmente. $O$ homem é apresentado como tendo seus direitos sexuais e reprodutivos garantidos, penalizado por roubo e usar maconha, enquanto que a mulher é posicionada a partir da sua saúde mental e sexual antes e após o aprisionamento e como cuidadoras. Esse ideal de cuidado associado ao feminino, que envolve a preservação de vínculos e relações familiares no contexto do cárcere, demonstra que essas questões tem implicações diferenciadas daquelas vivenciadas pelos homens. O gênero, nessa produção, refere-se a atributos culturais associados a cada um dos sexos, formando construções culturais e modelando as formas e representações de ser homem e ser mulher na sociedade.

\section{CONSIDERAÇÕES FINAIS}

A pesquisa aqui apresentada pretendeu ampliar a discussão sobre a saúde das mulheres no Sistema Prisional, focalizando o recorte de gênero que circula nos artigos nacionais e internacionais acessados e que foram publicados entre 2004 e 2015.

Ressaltamos que as produções apontam para as diferenças de gênero, sem apresentarem, entretanto uma discussão sobre uma teoria de gênero específica. Em sua maioria, refere-se ao gênero como todas as formas de construção social, cultural e linguística que diferenciam mulheres de homens e produzem seus corpos como corpos dotados de sexo, gênero e sexualidade. Gênero se apresenta como um conceito relacional, que implica mudanças nas relações sociais e nos deslocamentos das feminilidades e das masculinidades, sendo, portanto, produzido de forma articulada com outras marcas sociais, tais como classe, raça/etnia, sexualidade, geração, religião e nacionalidade (Cortina, 2015).

A diversidade de gênero é construída nas produções científicas analisadas, através dos símbolos, normas e instituições que definem modelos de masculinidades e feminilidades e padrões de comportamento aceitáveis ou não para homens e mulheres. Delimitando quais os campos de atuação 
para cada sexo e dando suporte à elaboração de leis e suas formas de aplicação.

Para desfamiliarizar a reprodução desse padrões de desigualdade e de discriminação, que legam às mulheres a manutenção de suas posições de inferioridade e exclusão social, é necessário considerar a implementação e monitoramento de políticas públicas transversais direcionadas ao sistema prisional, pensadas e aplicadas a partir da igualdade de gênero (Brasil, 2004).

Por todos os aspectos levantados no decorrer desse estudo, as produções científicas que focalizam as mulheres em situação de prisão sinalizam que elas representam uma das parcelas da população que por mais vezes sofreram sob os ciclos de reprodução de discriminação, violência e exclusão e, que, carecem de políticas públicas emergenciais que as fortaleçam para romper a lógica perversa que as mantêm à margem do exercício pleno da cidadania.

As desigualdades de gênero, expressas nos repertórios dos artigos analisados, tendem a demarcar outras desigualdades sociais e a discriminação de classe, raça/ etnia, idade, orientação sexual, etnia, deficiência, língua ou religião, dentre outras. Em suma, a atenção em saúde no sistema prisional feminino, apesar de já existirem políticas públicas direcionadas a essa população, apresenta situações de descaso e desatenção frente às demandas específicas das mulheres nesse contexto, incidindo com maior intensidade e se agravando devido ao não acesso a serviços de prevenção e tratamento adequados às suas especificidades de gênero.

\section{REFERÊNCIAS}

Alves, J., Dutra, A., \& Maia, A. (2013). História de adversidade, saúde e psicopatologia em reclusos: comparação entre homens e mulheres. Revista Ciência e Saúde Coletiva, 18 (3), 701 -709. Recuperado de http://www.scielo.br/scielo.php? script=sci_ arttext\&pid=S1 413-81232013000300016. doi: $10.1590 / \mathrm{S} 1413-81232013000300016$

Barcinski, M., \& Cúnico, S. D. (2014). Os efeitos (in) visibilizadores do cárcere: as contradições do sistema prisional. Revista da Associação Portuguesa de Psicologia, 28(2), 63-70. Recuperado de http://www.scielo.mec.pt/scielo.php?script=sci_ arttext\&pid=S0874-20492014000200006

Bezerra, A. T. A. F. (2015). HIV/AIDS e demais infecções sexualmente transmissíveis em população carcerária brasileira: uma revisão sistemática (Dissertação de mestrado). Escola Nacional de Saúde Pública Sergio Arouca, Fundação Oswaldo Cruz, Teresina, PI, Brasil. Recuperado de http://pesquisa.bvsalud.org/ aleitamentomaterno/resource/pt/lil-782464

Ministério da Saúde. Secretaria de Atenção à Saúde. Departamento de Ações Programáticas Estratégicas (2004). Política nacional de atenção integral à saúde da mulher: princípios e diretrizes. Brasília: Autor. Recuperado de http://bvsms.saude.gov.br/bvs/ publicacoes/politica_nac_atencao_mulher.pdf

Ministério da Saúde. Secretaria de Atenção à Saúde. Departamento de Atenção Básica. (2013). Saúde sexual e saúde reprodutiva. Brasília: Autor. Recuperado de http://bvsms.saude.gov.br/bvs/publicacoes/ saude_sexual_saude_reprodutiva.pdf

Ministério da Justiça. Departamento Penitenciário Nacional. (2014). Levantamento Nacional de Informações Penitenciária (INFOPEN-Mulheres). Recuperado de http://www.justica.gov.br/noticias/estudo-tracaperfil-da-populacao-penitenciaria-feminina-no-brasil/ relatorio-infopen-mulheres.pdf

Ministério da Saúde. (2014). A Política Nacional de Atenção Integral à Saúde das Pessoas Privadas de Liberdade no Sistema Prisional [Site]. Recuperado de http://dab. saude.gov.br/portaldab/pnaisp.php

Conselho Nacional de Justiça. (2016). Regras de Bangkok: Regras das Nações Unidas para o Tratamento de Mulheres Presas e Medidas Não Privativas de Liberdade para Mulheres Infratoras. Brasília: Autor. Recuperado de http://www.cni.jus.br/files/conteudo/ arquivo/2016/03/27fa43cd9998bf5b43aa2cb3eOf53c44.pdf

Carvalho, M. L., Valente, J. G., Assis, S. G., \& Vasconcelos, A. G. G. (2006). Perfil dos internos no sistema prisional do Rio de Janeiro: especificidades de gênero no processo de exclusão social. Ciência e Saúde Coletiva, 11 (2), 461-471. Recuperado de http:// www.scielo.br/scielo.php?script=sci_arttext\&pi$d=S 1413-81232006000200023$. doi: 10.1590/ $\underline{\mathrm{S} 1413-81232006000200023}$

Castillo, R.L. Cifuentes, S.V., Briceño, M.L., \& Noriega, K.R. (2014). Características del comportamento suicida encárceles de Colombia. Revista Criminalidad, 56(1), 83-95. Recuperado de http://www.scielo.org.co/scielo.php?pid=S1794-31082014000100006\&script=sci_abstract\&tlng $=p t$ 
Centro pela Justiça e pelo Direito Internacional. (2007). Relatório sobre mulheres encarceradas no Brasil. Recuperado de http://carceraria.org.br/wp-content/ uploads $/ 2013 / 02 /$ Relato $\% C C \% 81$ rio-para-OEA-sobre-Mulheres-Encarceradas-no-Brasil-2007.pdf

Cortina, M.O.C. (2015). Mulheres e tráfico de drogas: aprisionamento e criminologia feminista. Estudos Feministas, 23(3), 761-778. Recuperado de https://periodicos. ufsc.br/index.php/ref/article/view/41765/30378. doi: $10.1590 / 0104026 \times 2015 v 23 n 3 p 761$

Moraes, P. A. C., \& Dalgalarrondo, P. (2006). Mulheres encarceradas em São Paulo: saúde mental e religiosidade. Jornal Brasileiro de Psiquiatria, 55(1), 50-56. Recuperado de http://www.scielo.br/scielo.php?scrip$\mathrm{t}=$ sci_arttext\&pid=S0047-20852006000100007. doi: $10.1590 /$ S004720852006000100007

Guedes, M. A. (2006) Intervenções psicossociais no sistema carcerário feminino. Psicologia Ciência e Profissão, 26(4), 558-569. Recuperado de http:// pepsic.bvsalud.org/scielo.php?script=sci_arttext\&pi$\mathrm{d}=\mathrm{S} 141$ 4-98932006000400004.

Hale, G. J., Oswalt, K. L., Cropsey, K. L., Villalobos, G. C., Ivey, S.E., \& Matthews, C. A. (2009). The contraceptive needs of incarcerated women. Journal Womens Health (Larchmt), 18(8), 1221 -6. Recuperado de https:// www.ncbi.nlm.nih.gov/pubmed/19630555. doi: 10.1089/iwh.2008.1296

Fonseca, A. L., Braga, F. E. L., Silva, M. L. C., Camara, M. V., Marcondes, N. C., \& Lima, R. C. (2017). MulhereSemPrisão: desafios e possibilidades para reduzir a prisão provisória de mulheres. São Paulo: Instituto Terra, Trabalho e Cidadania/Fundo Brasil de Direitos Humanos/ Oak Foundation. Recuperado de http://ittc.org.br/ wp-content/uploads/2017/03/ITTC_MSP_VersaoDigital.pdf

Kramer, K., \& Comfort, M. (2011). Considerations in HIV Prevention for Women Affected by the Criminal Justice System. Womens Health Issues, $21(6), 272-273$. Recuperado de https://www.ncbi.nlm.nih.gov/pubmed/21782463. doi: 10.1016/i.whi.2011.05.009

Lermen H. S., Gil, B. L., Cúnico, S.D., \& Jesus, L. O. (2015). Saúde no cárcere: análise das políticas sociais de saúde voltadas à população prisional brasileira. Physis Revista de Saúde Coletiva, 25(3), $905-$ 924. Recuperado de http://www.scielo.br/scielo. php?pid $=$ S01 $03=73312015000300905$-\&scriptsci_abstract\&tlng =pt. doi: 10.1590/S0103$\underline{73312015000300012}$

Lima, G. M. B. (2005). Mulheres Presidiárias: Sobreviventes de um mundo de sofrimento, desassistência e privações (Dissertação de mestrado). Universidade Federal da Paraíba, João Pessoa, PB, Brasil. Recuperado de http://www.ccs.ufpb.br/ppgeold/dissertacoes2005/ dissertacaogigliolamarcos.pdf

Lima, G. M. B. (2013). A vida de mulheres na prisão: legislação, saúde mental e superlotação em João Pessoa - PB (Tese de doutorado). Fundação Oswaldo Cruz, Escola Nacional de Saúde Pública Sergio Arouca, Rio de Janeiro, RJ, Brasil. Recuperado de https://www.arca. fiocruz.br/handle/icict/20504

Lima, M. (2006). Da visita íntima à intimidade da visita: a mulher no sistema prisional (Dissertação de mestrado). Faculdade de Saúde Pública, Universidade de São Paulo, São Paulo, SP, Brasil. Recuperado de http:// www.teses.usp.br/teses/disponiveis/6/6136/tde24032008-085201/pt-br.php

Mello, D. C. (2008). Quem são as mulheres encarceradas? (Dissertação de mestrado). Faculdade de Psicologia, Pontifícia Universidade Católica do Rio Grande do Sul, Porto Alegre, RS, Brasil. Recuperado de http:// tede.pucrs.br/tde_arquivos/20/TDE-2009-0324T055431Z-1769/Publico/409563.pdf

Mejía-Ortega, L. M., Hernandéz-Pacheco, J., \& Nieto-López, E. (2011). Condiciones de accesibilidad a los servicios de salud de las internas e hijos convivientes en el centro de reclusión para mujeres el Buen Pastor de Medellín: 2009. Revista Gerenc Políticas Salud, 10(20), 121 -137. Recuperado de http://www.scielo.org.co/ pdf/rgps/v10n20/v10n20a09.pdf

Miranda, A. E., Merçon-de-Vargas, P. R., \& Viana, M. C. (2004). Saúde sexual e reprodutiva em penitenciária feminina, Espírito Santo, Brasil. Revista Saúde Pública, 38(2), 255-60. Recuperado de http://www.scielo.br/ pdf/rsp/v38n2/19786.pdf. doi: 10.1590/S0034$\underline{89102004000200015}$

Montuori, A. (2005). Literature review as creative inquiry: reframing scholarship as a creative process. Journal of Transformative Education, $1(10)$, 1-20. Recuperado de http://journals.sagepub.com/ doi/abs/10.1177/1541344605279381. doi: $10.1177 / 1541344605279381$

Lara, G. M., \& Cristina, G. (2008). Prevalência de anti-HCV, anti-HIV e co-infecção HCV/HIV em um presídio feminino do Estado do Rio Grande do Sul. Revista Brasileira Anal Clin, 40(2), 87-89. Recuperado de http:// pesquisa.bvs.br/brasil/resource/pt/lil-510326

Nicolau, A. I. O., Ribeiro, S. G., Lessa, P. R. A., Monte, A. S., Ferreira, R. C. N., \& Pinheiro, A. K. B. (2012). Retrato da realidade socioeconômica e sexual de mulheres presidiárias. Revista Acta Paul Enfermagem, 25(3), 386-392. Recuperado de http://www.scielo.br/pdf/ ape/v25n3/v25n3a1 1.pdf. doi: 10.1590/S0103$\underline{21002012000300011}$ 
Oliveira, L. V., Costa, G. M. C., Medeiros, K. K. A. S., \& Cavalcanti, A. L. C. (2013). Perfil epidemiológico de presidiárias no estado da Paraíba-Brasil: estudo descritivo. Online braz i nurs, 12 (4), 892-901. Recuperado de http://www.objnursing.uff.br/index.php/ nursing/article/view/4284. doi: 10.5935/1676$\underline{4285.20134284}$

Plugge, E., Douglas, N., Fitzpatrick, R. (2008). Patients, prisoners, or people? Women prisoners'experiences of primary care in prison: a qualitative study. British Journal of General Practice, 58(554), 630-8. Recuperado de https://www.ncbi.nlm.nih.gov/pubmed/18801272. doi: $10.3399 /$ bigp08X330771

Quitete, B., Paulino, B., Hauck F., Aguiar-Nemer, A. S., \& Silva-Fonseca, V. A. (2012). Transtorno de estresse pós-traumático e uso de drogas ilícitas em mulheres encarceradas no Rio de Janeiro. Revista de Psiq Clín, 39(2), 43-47. Recuperado de http://www.scielo. br/pdf/rpc/v39n2/01.pdf. doi: 10.1590/S0101 $\underline{60832012000200001}$

Ribeiro, M. A., Deus, N. M. S. F. (2017). O Encarceramento de Mulheres: o Cuidado e Controvérsias em Saúde. Atas do Congresso Ibero-Americano em Investigação Qualitativa, Salamanca, Espanha, 6. Recuperado de http:// proceedings.ciaiq.org/index.php/ciaiq2017/article/ view/1285/1244

Ribeiro, M. A. T., Martins, M. H. M., \& Lima, J. M. (2015) A pesquisa em base de dados: como fazer?. In Lang, $C$. E., Bernardes, J. S., Ribeiro, M. A. T., \& Zanotti, S. V. (Orgs.), Metodologias: Pesquisas em Saúde, clínica e práticas psicológicas (pp. 61-83). Maceió: EDUFAL.

Spink, M. J. (2004). Práticas discursivas e produção de sentidos no cotidiano: aproximações teóricas e metodológicas (3a ed.). São Paulo: Cortez.

Spink, M. J. P., Medrado, B. (2013). Produção de Sentido no Cotidiano. In Spink, M. J. P. (Org.), Práticas discursivas e produção de sentidos no cotidiano: aproximações teóricas e metodológicas. Petrópolis: Centro Edelstein de Pesquisas Sociais.

Scherer, Z. A. P., Scherer, E. A., Nascimento, A. D., \& Ragozo, F. D. (2011). Perfil sociodemográfico e história penal da população encarcerada de uma penitenciária feminina do interior do estado de São Paulo. SMAD, Revista Eletrônica Saúde Mental Álcool Drog. (Ed. Port.), 7 (2), 55-62. Recuperado de http://www.revistas. usp.br/smad/article/view/49572. doi: 10.11606/ issn. 1806-6976.v7i2p55-62

Walker, S. (2015). Literature reviews: generative and transformative textual conversations. FQS, 16(3), 1-13. Recuperado de http://www.qualitative-research.net/ index.php/fqs/article/view/2291. doi: 10.17169/ fas-16.3.2291 